\title{
LETTER
}

\section{CORE-REA: COPD right heart and respiratory acidosis}

\author{
Jean-Loup Augy ${ }^{1,2^{*}} \mathbb{D}$, Jean-Luc Diehl ${ }^{1,2}$, Clotilde Bailleul $^{1}$, Bertrand Hermann ${ }^{1}$, Emmanuel Guerot ${ }^{1}$, \\ Damien Vimpere ${ }^{1}$ and Nadia Aissaoui ${ }^{1,3}$
}

C 2019 Springer-Verlag GmbH Germany, part of Springer Nature

Dear editor,

Influence of respiratory acidosis on right ventricular (RV) function in severe acute exacerbation (AE) of chronic obstructive pulmonary disease (COPD) patients remains unclear. Although lactic acidosis with $\mathrm{pH}<7.10$ could decrease contractile function in cardiomyocytes [1], respiratory acidosis with $\mathrm{pH}<7.20$ and $\mathrm{PaCO}_{2}>90 \mathrm{mmHg}$ may increase cardiac output [2] or increase RV afterload [3] and systolic pulmonary artery pressure (sPAP) [4].

We aimed to detect influence of $\mathrm{PaCO}_{2}$ decrease induced by the extracorporeal $\mathrm{CO}_{2}$ removal $\left(\mathrm{ECCO}_{2} \mathrm{R}\right)$ on the RV function in AE-COPD patients requiring invasive mechanical ventilation (IMV).

This was a monocentric observational ancillary study of the REXECOR study (NCT02965079). According to our local protocol, $\mathrm{ECCO}_{2} \mathrm{R}$ was implanted if $\mathrm{PaCO}_{2}$ remained $>55 \mathrm{mmHg}$ and intrinsic positive end-expiratory pressure (PEEP) $>5 \quad \mathrm{cmH}_{2} \mathrm{O}$ in IMV AE-COPD patients with the following mechanical ventilator parameters: tidal volume $(\mathrm{VT}): 8 \mathrm{~mL} / \mathrm{kg}$, respiratory rate (RR): $12 / \mathrm{min}$ in the assist-controlled mode. Hemolung ${ }^{\circledR}$ (ALung, Pittsburgh, USA) was the device used during the study period. IMV parameters (PEEP, VT and RR) were kept unmodified during $2 \mathrm{~h}$ before and one after the initiation of $\mathrm{ECCO}_{2} \mathrm{R}$. Transthoracic echocardiographic (TTE) studies were performed at baseline and $1 \mathrm{~h}$ after starting $\mathrm{ECCO}_{2} \mathrm{R}$. Respiratory parameters were simultaneously collected. The RV systolic function was assessed by the $\mathrm{S}^{\prime}$ wave at tricuspid annulus ( $\mathrm{S}^{\prime}$ wave) and

\footnotetext{
*Correspondence: jeanloup.augy@aphp.fr

1 Department of Critical Care Unit, Assistance Publique-Hôpitaux de Paris (AP-HP), Hôpital Européen Georges Pompidou (HEGP), 20 rue Leblanc, 75015 Paris, France

Full author information is available at the end of the article
}

the TAPSE [5]. We chose $\mathrm{S}^{\prime}$ wave at tricuspid annulus ( $\mathrm{S}^{\prime}$ wave) and the TAPSE, as surrogate of RV function as they were found to be less load dependent compared to RV dimensions in critically ill patients [6].

All data assessing RV and LV functions were recorded using TTE according to guidelines from the American Society of Echocardiography and the European Association of Cardiovascular Imaging (electronical supplemental material (ESM) 1).

Seven patients [ 5 women, median age 63 years (IC25-75: 56-73), median body mass index $39.5 \mathrm{~kg} / \mathrm{m}^{2}$ (IC25-75: 24.1-47.0)] were included from 11/2017 to 02/2018. Median SAPS2 at admission was 32 (IC25-75: 29-40) and respiratory SOFA was 3 (IC25-75: 2-3).

All patients had RV hypertrophy defined as RV free wall superior to $5 \mathrm{~mm}$. Interestingly, no RV dysfunction was reported according to $\mathrm{S}^{\prime}$ wave and TAPSE values (Table 1, ESM).

The implantation of $\mathrm{ECCO}_{2} \mathrm{R}$ led to a significant reduction of $\mathrm{PaCO}_{2}$ from $68 \mathrm{mmHg}$ (IC25-75: 67-75) to $57 \mathrm{mmHg}$ (IC25-75: 52-59), $p<0.009$.

The evolutions of the main clinical and biological parameters are reported on ESM, Table 2. Figure 1 shows evolution of $\mathrm{RV}$ parameters and $\mathrm{PaCO}_{2}$ before and after implantation of $\mathrm{ECCO}_{2} \mathrm{R}$. There was no difference between $S^{\prime}$ wave values before or after reduction of $\mathrm{PaCO}_{2}$ induced by $\mathrm{ECCO}_{2} \mathrm{R}(p=0.16)$, whereas systolic pulmonary artery pressures (sPAP) decreased from $50.0 \mathrm{mmHg}$ (IC25-75: 44.5-55.5) to $45.0 \mathrm{mmHg}$ (IC25-75: 37.5-46.0), $p=0.04$. Of note, there was a trend toward a decrease in PVR from 2.00 UW (IC25-75: $1.73-2.53$ ) to $1.75 \mathrm{UW}$ (IC25-75: 1.53-2.12), $p=0.07$.

Despite some limitations due to the study design including small sample size, we conducted the first physiological study in a homogeneous population. The

\section{Springer}




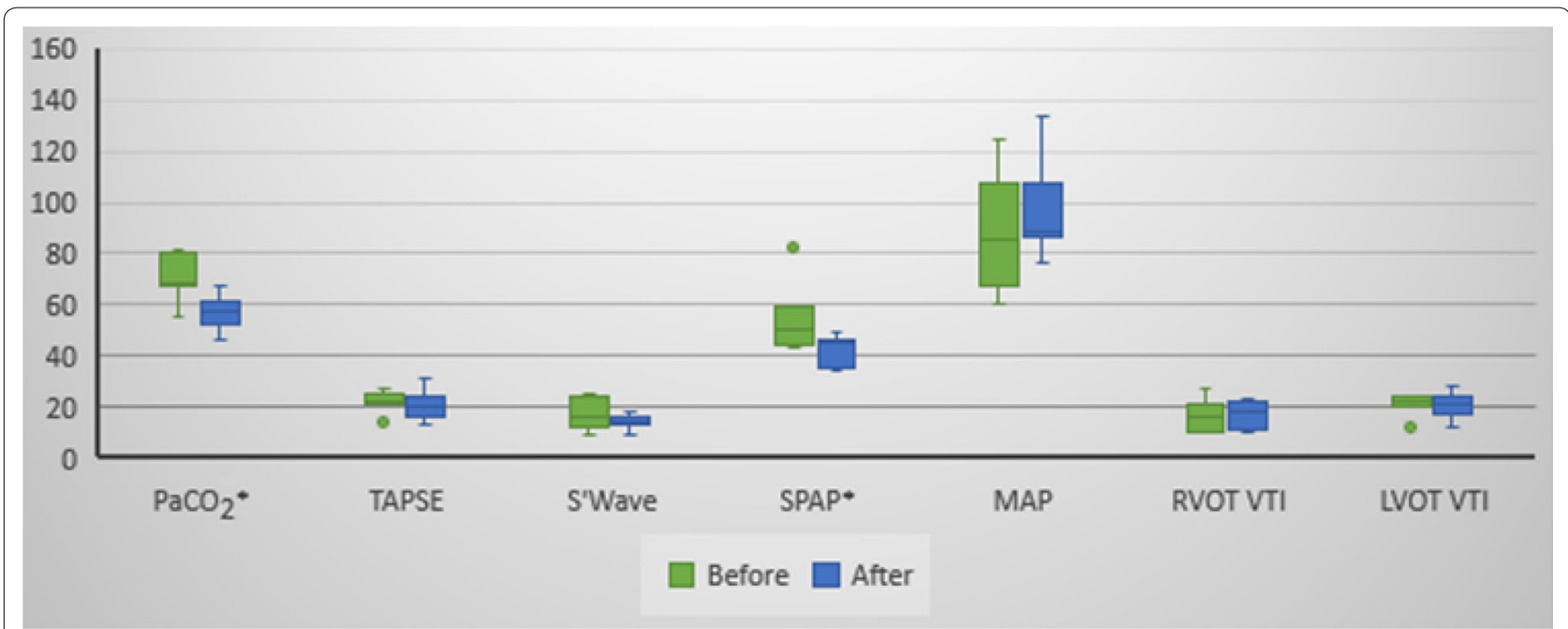

Fig. 1 Evolution of RV echocardiographic parameters according to $\mathrm{PaCO}_{2}$ variations. $\mathrm{PaCO}_{2}$ arterial $\mathrm{CO}_{2}$ partial pressure, TAPSE tricuspid annular plane systolic excursion, S' wave S' wave at tricuspid annulus, SPAP systolic pulmonary arterial pressure, MAP mean arterial pressure, RVOT VTI right ventricular outflow tract velocity time integral, LVOTVTI left ventricular outflow tract velocity time integral. Results are exprimed in median and IC25-75, extreme values are showed; ${ }^{*}<<0.05$

decrease in $\mathrm{PaCO}_{2}$ in $\mathrm{AE}-\mathrm{COPD}$ patients requiring IMV induces decrease in sPAP without modifying the RV systolic parameters. It also leads to an afterload drop reflected by the PVR decrease even though our results did not reach statistical significance.

\section{Author details}

${ }^{1}$ Department of Critical Care Unit, Assistance Publique-Hôpitaux de Paris (APHP), Hôpital Européen Georges Pompidou (HEGP), 20 rue Leblanc, 75015 Paris, France. ${ }^{2}$ Université Paris Descartes, INSERM UMR_S1140, Paris, France. ${ }^{3}$ Université Paris-Descartes, INSERM U970, Paris, France.

\section{Supplementary information}

Supplementary information accompanies this paper at https://doi. org/10.1007/s00134-019-05748-1.

\section{Compliance with ethical standards}

\section{Conflicts of interest}

Dr. JL. Diehl reported receiving research support and personal fees from Alung and Novalung/Xenios.

\section{Publisher's Note}

Springer Nature remains neutral with regard to jurisdictional claims in published maps and institutional affiliations.

\section{Accepted: 11 August 2019}

Published online: 30 August 2019

\section{References}

1. Wildenthal K, Mierzwiak D, Myers R, Mitchell J (1968) Effects of acute lactic acidosis on left ventricular performance. Am J Physiol-Leg Content 214:1352-1359. https://doi.org/10.1152/ajplegacy.1968.214.6.1352

2. Stengl M, Ledvinova L, Chvojka J et al (2013) Effects of clinically relevant acute hypercapnic and metabolic acidosis on the cardiovascular system: an experimental porcine study. Crit Care 17:R303. https://doi. org/10.1186/cc13173

3. Morimont P, Guiot J, Desaive T et al (2015) Veno-venous extracorporeal CO2 removal improves pulmonary hemodynamics in a porcine ARDS model. Acta Anaesthesiol Scand 59:448-456. https://doi.org/10.1111/ aas. 12497

4. Karagiannidis C, Strassmann S, Philipp A et al (2015) Veno-venous extracorporeal CO2 removal improves pulmonary hypertension in acute exacerbation of severe COPD. Intensive Care Med 41:1509-1510. https:// doi.org/10.1007/s00134-015-3917-8

5. Rajagopal S, Forsha DE, Risum N et al (2014) Comprehensive assessment of right ventricular function in patients with pulmonary hypertension with global longitudinal peak systolic strain derived from multiple right ventricular views. J Am Soc Echocardiogr 27:657-665.e3. https://doi. org/10.1016/j.echo.2014.02.001

6. Aissaoui N, Guerot E, Combes A et al (2012) Two-dimensional strain rate and Doppler tissue myocardial velocities: analysis by echocardiography of hemodynamic and functional changes of the failed left ventricle during different degrees of extracorporeal life support. J Am Soc Echocardiogr 25:632-640. https://doi.org/10.1016/j.echo.2012.02.009 